\title{
Platypnoea-orthodeoxia syndrome due to right to left interatrial shunting despite normal intracardiac pressures
}

\author{
H Karunatilake ${ }^{1}$, K Vithiya ${ }^{1}$, V Jeevagan ${ }^{1}$, S Subadra ${ }^{1}$
}

\section{Introduction}

Platypnoea-orthodeoxia syndrome (POS) is a rare condition in which hypoxaemia and breathlessness occur when upright and resolve when prone. POS has been reported in association with intracardiac and intrapulmonary shunting [1]. This case describes a patient who presented with hypoxaemia and platypnoea and investigations showed an interatrial defect with right to left shunt, without pulmonary hypertension.

\section{Case report}

A 45-year old man was admitted with worsening shortness of breath. He was breathless on exertion and felt more so when seated and was relieved when lying flat. Three months prior to admission he underwent a tube thoracostomy for a suspected pneumothorax after falling from a height. When breathing room air his oxygen saturation was $90 \%$ in the supine position and $82 \%$ in the erect position. During the Valsalva manoeuvre it dropped to $78 \%$ with little or no improvement with inspired oxygen. He looked plethoric, and his haemoglobin was $17.7 \mathrm{~g} / \mathrm{dl}$ with a haematocrit of 55\%. Examination of the abdomen was normal. Arterial blood gas showed significant hypoxaemia $\left(\mathrm{po}_{2} 68 \mathrm{mmHg}\right.$ ). Lung functions, chest CT and CT pulmonary angiogram were normal. 99 mTc pulmonary perfusion scan ruled out pulmonary embolism, but high tracer uptake in the systemic side suggested a right to left shunt. Trans-thoracic echocardiography failed to reveal an intra-cardiac shunt. Trans oesophageal echocardiography showed an atrial septal defect and the contrast crossing confirmed a right to left shunt. Estimated tricuspid pressure gradient was only $28 \mathrm{mmHg}$. While awaiting right heart catheterisation he developed an ischaemic stroke involving the right parietal lobe. He developed acute hydrocephalus and underwent ventriculo-peritoneal shunt insertion. Thrombophilic screening, including prothrombin gene mutation, was negative. He recovered fully from the stroke, without any residual neurological deficit. A subsequent cardiaccatheter study showed normal pulmonary venous drainage. There was no pulmonary arteriovenous fistula. Mean pulmonary artery pressure was $12 \mathrm{mmHg}$. He underwent a device closure of the atrial septal defect. After the procedure platypnoea and orthodeoxia resolved

${ }^{1}$ Medical Unit, Base Hospital, Chilaw, Sri Lanka.

Correspondence: HK, e-mail <sanyalharindra@yahoo.com>. Received 19 April and revised version accepted 9 October 2010. Competing interests: none declared.

Vol. 55, No. 4, December 2010 
completely. He returned to previous physical activity and remained symptom free. Two months later echocardiography showed no residual shunt. His blood gases, red cell count and the haemoglobin were within the normal range.

\section{Discussion}

Normally, an interatrial communication allows left to right flow along the pressure gradient. A right to left flow exists when pressure alterations in the pulmonary circulation occur causing pulmonary hypertension and reversal of the pressure gradient. However, right to left shunting in patients with interatrial defects with normal right heart pressures has been reported [2]. Godart et al reported 11 patients with atrial right to left shunting despite normal right sided pressure. Six of them had platypnoea and orthodeoxia [3]. Galve et al reported six patients with uncomplicated atrial septal defects who had right to left shunting without pulmonary hypertension [4]. Therefore it is important to consider a possible right to left shunt in a cyanotic patient even in the presence of normal pulmonary pressure.

How can this "water flowing uphill” be explained? There are several postulated mechanisms. Flow phenomenon is where blood from the inferior vena cava (IVC) is preferentially directed towards the fossa ovalis and the interatrial defect causing a right to left shunt with normal pulmonary pressures. Change in the axis of the interatrial septum due to dilation of the aortic root and after pneumonectomy or abdominal surgery can place the atrial defect directly in line with the blood flow from the IVC [5]. Furthermore, an over-developed eustachian valve can direct blood from the IVC towards the left atrium [5]. In our patient repeated echocardiographs failed to show such a valve. Possible anatomical distortion and positional modification during thoracostomy favouring the right to left shunt could explain the late presentation of our patient. Another possible explanation is a change in the compliance of the right heart chambers resulting in diastolic pressure differentials causing a right to left shunt [6]. This theory is supported by the fact that most of the patients present at an advanced age. Three of the 4 patients reported before had scarring and fibrosis of the right ventricle affecting its compliance [7]. Though the mechanism is not fully explained, more blood flowing through the shunt during upright posture may explain the orthodeoxia.

As evident in our patient a right to left shunt is an important cause of paradoxical embolism and stroke. A study of 503 stroke patients confirmed an association between a patent foramen ovale and cryptogenic strokes and suggested paradoxical embolism as the cause of stroke [8]. Occlusion of the atrial defect resulted in complete resolution of symptoms in our patient. Transcatheter occlusion is the preferred method in compatible cases [3].

Diagnosis of this condition depends on awareness of its pathophysiology. The presence of an intra cardiac defect and a right to left shunt is established by contrast echocardiography. A trans-oesophageal echocardiograph is preferred. Valsalva manoeuvre during the procedure may facilitate the diagnosis. To demonstrate the preferential blood flow from the IVC through the defect, contrast should be given to a leg vein.

\section{Acknowledgments}

We thank Dr. Ruwan Ekanayake and Dr. Gamini Galappaththi for the cardiac investigations and the device closure.

\section{References}

1. Kubler P, Gibbs H, Garrahy P. Platypnoea-orthodeoxia syndrome. Heart 2000; 83: 221-3.

2. Thomas JD, Tabakin BS, Ittlleman FP. Atrial septal defect with right to left shunt despite normal pulmonary artery pressure. Journal of the American College of Cardiology 1987; 9: 221-4

3. Godart F, Rey C, Prat A, et al. Atrial right-to-left shunting causing severe hypoxaema despite normal right-sided pressures. European Heart Journal 2000; 21: 483-9.

4. Galve E, Angel J, Evangelista A, Anivarro I, PermanyerMiralda G, Soler-Soler J. Bidirectional shunt in uncomplicated atrial septal defect. British Heart Journal 1984; 51: 480-4.

5. Gallaher ME, Sperling DR, Gwinn JL, Meyer BW, Fyler DC. Functional drainage of the inferior vena cava into the left atrium-three cases. American Journal of Cardiology 1963; 12: 561-6.

6. Ciafone RA, Aroesty JM, Weintraub RM, LaRaia PJ, Paulin S. Cyanosis in uncomplicated atrial septal defect with normal right cardiac and pulmonary arterial pressures. Chest 1978; 74: 596-9.

7. Strunk BL, Cheitlin MD, Stulbarg MS, Schiller NB. Rightto-left interatrial shunting through a patent foramen ovale despite normal intracardiac pressures. American Journal of Cardiology 1987; 60: 413-5.

8. Handke M, Harloff A, Olschewski M, Hetzel A, Geibel A. Patent foramen ovale and cryptogenic stroke in older patients. New England Journal of Medicine 2007; 357: 2262-8. 